\title{
'SELFIE ELBOW'- A PUBLIC HEALTH PROBLEM AMONG MOBILE USERS
}

\author{
Khanal $L^{1^{*}}$, Khan $G A^{2}$, Pandeya $A^{3}$
}

\section{Affiliation}

1. Assistant Professor, Department of Human Anatomy, B.P. Koirala Institute of Health Sciences, Dharan, Nepal

2. Assistant Professor, Department of Anatomy, Chitwan Medical College, Chitwan, Nepal

3. Lecturer, Department of Anatomy, Devdaha Medical College and Research Institute, Rupandehi, Nepal

\section{ARTICLE INFO}

\section{Article History}

$\begin{array}{ll}\text { Received } & : \text { 5 September, } 2018 \\ \text { Accepted } & : \quad 23 \text { April, } 2019 \\ \text { Published } & : \quad 30 \text { April, } 2019\end{array}$

(C) Authors retain copyright and grant the journal right of first publication with the work simultaneously licensed under Creative Commons Attribution License CC - BY 4.0 that allows others to share the work with an acknowledgment of the work's authorship and initial publication in this journal.

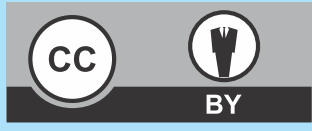

MRA 1

DOI: http://dx.doi.org/10.3126/bjhs.v4i1.23952

\author{
* Corresponding Author \\ Dr Laxman Khanal \\ Assistant Professor \\ Department of Human Anatomy \\ B.P. Koirala Institute of Health Science, Dharan, Nepal \\ Email ID : laxman.khanal.bpkihs@gmail.com \\ Orcid ID: https://orcid.org/0000-0002-1304-0103
}

\section{Citation}

Khanal L, Khan GA, Pandeya A. 'selfie Elbow'- A Public Health Problem Among Mobile Users. BJHS 2019;4(1)8: 675-679

\section{HIGHLIGHTS}

- The American Psychiatric Association (APA) has officially confirmed the taking selfies as a mental disorder and named it 'selfitis'.

- Selfie elbow' is a condition of overuse injury and micro-trauma of the muscles and tendons at elbow caused by twisting and extending the arm for taking too many selfies photos.

- During the period from 2014 to 2016, 52 deaths were recorded globally of which 25 cases belonged to India.

- Use of icepacks, muscle exercise, medications, and use of selfie sticks for reducing the stress are suggested by experts for the management of 'selfie elbow'.

\section{ABSTRACT}

While taking a selfie picture, a person is in a position in which the arm is fully extended or sometimes a little bent and maintained until the picture of choice is adjusted in the camera frame. One Person must have a firm grip on phone to hold it and hit click. When the process is repeated for a few photos, it causes repetitive strain injury, resulting in various signs, including pain in the elbow joint, which has now been named 'selfie elbow.' Doctors assume that as many as $25 \%$ of cellphone users in Kolkata are suffering from this problem (selfie-elbow).

Although a selfie is generally seen as an expression of self to others, the American Psychiatric Association (APA) has officially confirmed that taking 'selfies' is seen as a mental disorder and has been given the term 'selfitis.' Selfie elbow is a condition due to overuse injury caused by extending and twisting one's arm for too many phone selfies. Like tennis elbow or golfer's elbow, an addiction to selfie-taking and clicking too many can cause pain in your primary picturesnapping elbow and may affect the upper limb, elbow, and shoulder muscles - which leads to degradation in function.

Joints involved in the process of selfie-taking are the shoulder joint, the elbow joint, and the wrist joint, all of which help the hand attain a perfect frame for the picture. However, most of the strain is referred to the elbow, because the person extends (or sometimes bends) the elbow in an extremely strained position during the selfie. Selfie elbow is more of an abnormal and repetitive loading of muscles around the elbow, leading to microruptures, and resulting in inflammation and pain; this ultimately heals with scarring, but causes recurrent pain. As stated, it is a form of repetitive stress injury, similar to carpal tunnel syndrome (or the compression of the median nerve in the wrist, usually due to overuse of the hand) and tendonitis (which occurs when the tendon becomes inflamed).

\section{KEYWORDS}

Elbow Joint, overuse injuries, inflammation, carpal tunnel syndrome, tendonitis. 


\section{INTRODUCTION}

It is very difficult to say whether the newer technologies for example mobile phones are boon or bane. It has become an indispensable tool in the hands of young generation. It has replaced a watch, calendar, calculator, camera, radio, phone book etc. ${ }^{1,2}$ Selfies are popular, and not just popular among our youth, but popular across all generations! MerriamWebster dictionary defines selfie as 'an image of oneself taken by oneself using a digital camera especially for posting on social networks'. ${ }^{4}$ The term 'selfie' appear in paper or electronic medium first time on $13^{\text {th }}$ of September 2002 in an Australian internet forum by an Australian person (Nathan Hope). Oxford English Corpus, which is an archive of electronically stored structured set of texts, collected millions of words each month. This database was analysed by Oxford English Dictionary (OED) in daily basis to track new and emerging words. On the basis of statistical analysis the OED declared the word of the year 2013 as 'selfie'.

Selfie photographs like all photograph are posted online to express and to convey a particular impression of oneself. ${ }^{6}$ Due to this reason, selfies are very popular nowadays. Millions of selfies are becoming a new medium for selfexpression and self-representation through various social media to keep themselves in other people's minds.' People became crazy in taking selfies and got into problems. ${ }^{1}$ During the period from 2014 to 2016, 52 deaths were recorded globally of which 25 cases belonged to India. ${ }^{8,12}$ Even though taking selfies is taken as a way of expression of oneself to others, the American Psychiatric Association (APA) has officially confirmed the taking selfies as a mental disorder and named it 'selfitis'. It defines 'selfitis' as an obsessive compulsive desire to take one's photos and post those on social media as a way of getting compensation of lack of selfesteem and gap in intimacy. ${ }^{13-14}$

This smartphone obsession has already lead to variety of well-documented tech injuries like text claw, iPad hand, muscle problems, osteoarthritis and even tendinitis of the thumbs. ${ }^{15-17}$ "Selfie elbow" is the latest one among them. ${ }^{18}$ Selfie elbow is a condition of overuse injury caused by twisting and extending the arm for taking too many selfies photos. Repetitive overuse, stretching and awkward positioning resulted in microtrauma or continuous stress of the muscles and tendons at the elbow. ${ }^{19}$ Muscles and tendons work to keep the muscle attached to the bone as well as help extend and stabilize the wrist. ${ }^{20}$ Like in the tennis elbow or golfer's elbow, multiple selfies taking and clicking may cause pain in the primary picture snapping elbow and it may further affect shoulder muscles which may lead to compromise in normal functions. ${ }^{21}$ Even in people who do not have habit of being involved in sport like tennis or golf requiring repetitive use of extended arm and jerks on the elbow, are found to have pain and other similar symptoms of sport related injuries. ${ }^{22}$ This latest tech injury is named as selfie elbow. ${ }^{23}$ Experts of 'shoulder surgery department' claims that there is always a possibility of injury to joints like elbow by incorrect stretching of the tendons. ${ }^{21}$ One case of an American journalist, HodaKotb, was found to be reported for her affection of selfies, but the high prevalence of taking selfies suggest that there are many more undiagnosed cases in different part of world..$^{23}$ Doctors in Kolkata (India) were puzzled when more numbers of youngster visit them with the complaint of elbow pain, later it was revealed that those youngsters were involved in taking too many selfies for uploading in social media. Doctors assumed that around $25 \%$ of cellphone users in Kolkata are suffering from 'selfie elbow'. ${ }^{24}$ Since taking selfies is a new fad, the experts suggest that the number of patients will rise in near future. Though normal gaming, chatting or texting on cellphone may lead to similar condition, taking selfies could hasten the injury since the process of taking selfies involve raising the arm in abnormal way for longer period of time. ${ }^{24}$

\section{ANATOMICAL CONSIDERATION}

Shoulder joint, elbow joint and wrist joint help the upper arm to attain a position for perfect frame for the picture, so are the joints involved in process of selfie taking. Despite the involvement of these joints, most of the strain is taken by the elbow because a person extends and bends a bit the elbow in an extremely strained state during capturing the selfie. Such a strained posture of the upper limb is responsible for the repetitive strain and overuse of the structures around the elbow making it a target joint for selfie elbow. Pain and discomfort in elbow is thought to be due to inflammation and micro-rupture of the tendons passing through the elbow joint due to repetitive motion. ${ }^{20}$

Knowledge of functional anatomy and biomechanics of the elbow is very important. The elbow joint is a joint between the lower end of the humerus and upper ends of the radius and ulna. It is the hinge type of synovial joint. Stability of the elbow joint is provided by the pulley shaped trochlea of the humerus and jaw like trochlear notch of the ulna and ligaments. ${ }^{25}$ The complexity of the joint is increased by its continuity with the superior radio-ulnar joint. It includes two articulations: the humero-ulnar, between the trochlea of the humerus and the ulnar trochlear notch, and the humeroradial, between the capitulum of the humerus and the radial head. ${ }^{20}$

Most of the ligaments are in real sense specialized thickening of the joint capsule. The elbow joint has six degrees of freedom: flexion/extension, pronation/supination, and valgus/varus functional motions. ${ }^{26}$ Elbow has mainly medial and lateral collateral ligaments with former having two parts: anterior bundle and posterior bundle. Due to slight difference in origin of ligaments, lateral collateral ligament (LCL) becomes tense uniformly during elbow flexion and extension, while medial collateral ligament $(\mathrm{MCL})$ is taut at different position during elbow flexion. $\mathrm{LCL}$ in general takes its origin from the lateral epicondyle of the humerus and terminates diffusely in the annular ligament, while MCL get its origin from the medial epicondyle and got attached itself to the coronoid and olecranon processes of ulna. The LCL and the anterior bundle of the MCL originate from points through which the axis of rotation passes. ${ }^{26}$ 
There are seven muscles in the back of the forearm crossing the elbow joint. Among these, most lateral one is the extensor carpi radialis brevis (ECRB) which is covered by extensor carpi radialis longus (ECRL). ${ }^{19}$ In addition to the lateral epicondyle, ECRB has its origin from the LCL and intermuscular septa. The tendon of ECRB inserted on Lateral side of the dorsal surface of the base of third metacarpal bone. Study of ECRB by electromyography had shown its strong activity at all time during routine functional activities, but the main action of this muscle is pure wrist extension with some degree of radial deviation. ${ }^{7-27}$

\section{PATHOPHYSIOLOGY}

In precise sense selfie elbow is an abnormal and repetitive loading of muscles around the elbow causing micro-rupture and inflammation of tendons leading to pain and discomfort, which ultimately heals with scarring and might cause recurrent pain. It is a form of repetitive stress injury, similar to carpal tunnel syndrome (caused by median nerve compression in the wrist, usually due to overuse of the hand) and tendonitis (occurs when the tendon becomes inflamed). ${ }^{23,28}$ Such pathological changes in elbow may initiate severe pain with minimal stress causing painful inhibition of muscles resulting in further weakening. Repeated painful inhibition of muscles may build up stress through such vicious cycle and lead to severe loss of function. ${ }^{29}$ Nothing in human evolution necessitated the arm to be extended till your ligaments begin stretching, your palm to be turned inward, and the thumb to be bent at an unnatural angle to tap the screen continuously while craning your neck to fit in the frame. ${ }^{24}$

Any abnormal posture is going to put muscles and bones under stress. Taking selfies involve an unusual arm position and repeating the act could be injurious and stressful. Keeping arm raised for long time to click selfies causes the elbow muscles under severe strain. Repeating the same action eventually makes the elbow muscles under strain and puts pressure on the bone, leading to inflammation and severe pain. ${ }^{24}$

Muscle causing the extension and flexion of elbow joints are mainly originated from the lateral and medial epicondyle of the humerus respectively. Tearing of tendon of extensor carpi radialis brevis (ECRB) lead to lateral epicondylitis during activities requiring repetitive supination and pronation of the forearm with full extension of the elbow joint. ${ }^{26}$

\section{Signs and Symptoms:}

Clicking selfies initially starts with fun and time pass, but gradually it becomes habit and followed by an obsession. Consequences of selfie includes poor performance in the work field, peer pressure, unwanted stress, unhealthy family relations, conflicts etc. ${ }^{30}$ Also, it may lead to complications such as swelling in elbow followed by pain and numbness in the elbow joint, cervical spondylitis and awkward posture of the body. ${ }^{30}$ Some cases were also found to have their shoulder froze during taking the selfies followed by pain in shoulder joint. ${ }^{24}$ A study done among 250 students aged 18 to 25 year had shown that taking selfie was associated with complications like low back pain (30\%), head ache $(25 \%)$, cervical spondylitis (20\%), stress (15\%) and selfie elbow (10\%).

There may be the swelling in the elbow joint more specifically at the site of origin of extensor group of muscles because most of the stress in the position of taking selfie is carried out by the extensor group of muscles. ${ }^{7}$ Once the injury of the tendon and ligament occurred, even minimal amount of load or strain causes a lot of pain due to already weakened muscles of the elbow which has not been cured yet, and this eventually lead to loss of function. ${ }^{22}$

Symptoms of the selfie elbow can be pointed out in following points:

1. Burning pain around the elbow joint

2. Pain while doing actions at elbow and wrist

3. Limitation of motion at elbow and wrist joint

4. Stiffness in the arm (more commonly in morning)

5. Muscle fatigueness

\section{PREVENTION AND MANAGEMENT}

According to experts, it is suggested that applying ice packs and taking some anti-inflammatory medications may be needed in case of emergency. ${ }^{29}$ It may require a physiotherapist for modalities and muscle stretching and strengthening exercises if the trouble rises. The experts also suggested the use of a selfie stick to avoid stress on the muscles and use both hands alternatively to take selfies which prevents build-up of stress on only one arm muscle group. ${ }^{29}$ Using both hands alternatively is a wise option. This prevents the overuse of particular arm. Since, selfie elbow is very similar to tennis elbow, both triggered by stress resulting from overuse, resting the arm joints is the first step for the both conditions. ${ }^{24}$ Following methods could be applied for the management of selfie elbow:

1. Rest: give rest to your arm. Since 'selfie elbow' is an overuse injury, it is the first thing to be done. Avoid clicking too many selfies. Use a selfie stick or use both hands while holding your phone during a click, or switch hands to avoid overuse of one hand.

2. Ice: It works for acute inflammatory symptoms only when there is a visible and palpable swelling around the area. Ice is recommended for its analgesic and local vasoconstrictive action, but for chronic condition and cases with muscle dysfunction inflammation could not respond with icing. ${ }^{31}$

3. Medication: non-steroidal anti-inflammatory drugs (NSAIDs) could be used to reduce the inflammation and pain. $^{31}$

4. Physiotherapy: Perform full range active movement of the elbow. Other modalities of exercise like Therapeutic eccentric exercise (TEE) could be suggested for structural remodeling of the tendon and to increase the tensile strength of the tendon. ${ }^{32}$ TEE may provide neuromuscular adaptation of both agonist and antagonist muscles. ${ }^{33}$ 
Some of the simple exercises are also suggested for the affected persons are:

a) Wrist flexion and extension stretch: Keeping your elbow straight, use your unaffected hand to bend the affected wrist downward, hold this stretch for 30 seconds. Still keeping your elbow straight, use your unaffected hand to bend the wrist upward and hold this stretch for 30 second. Whole action should be repeated two times. ${ }^{3,34,35}$

b) Wrist flexion curls: Hold a small free weight with the affected hand, rest the forearm on a table and bend the wrist up and down with the palm face up and repeat the same for ten times. ${ }^{3,34,35}$

c) Putty squeeze: Squeeze putty in hand trying to keep it round by rotating putty after each squeeze. Push fingers through putty to palm each time for two minutes. ${ }^{3,34,35}$

5. Braces and Support: Use of elbow caps to support the elbow joint while in pain may be useful. Braces should not be used for longer span of time because braces for longer time may enhance the muscle weakness and may promote immobility to some extent. $^{22}$

In order to save young generation from being selfie- addict, several remedies should be adopted which include behavioral counseling and cognitive behavior therapy for self-motivation and self-control on unnecessary use of social media and giving quality time to family and friends. $19,{ }^{36}$ Of course, the cure would be to stop taking so many selfies. ${ }^{23}$

\section{CONCLUSION: STRESS}

Taking more selfies makes people self-obsessed with poor mental health, are mentally disturbed and seen with conditions like mood swings and stress. Taking selfie also causes physical problem like Selfie elbow. It can be concluded that taking selfie is fun in one hand with simultaneous negative impact on human health in the other hand. This condition can be prevented and cured by administering various method of remedies discussed.

\section{REFERENCES}

1. Subrahmanyam B, Subba Rao, K, Sivakumar, Chandra Sekhar G. Selfie Related Deaths Perils of Newer Technologies. Narayana Med.J.2016;5:52-6.

2. Suhag A, Larik R, Mangi G, Khan M, Abbasi S, Madiha H. Impact of Excessive Mobile Phone Usage on Human. J. Comput. Sci. Syst. Biol.2016;09:173-7.

3. PTClinics. How to Relieve Selfie Elbow- Yes, it's a thing [internet]. California:PT clinic; 2018[cited 2018 November 20] Available from: https://ptclinics.com/how-to-relieve-selfie-elbow-yes-its-a-thing.

4. Merriam-Webster medical dictionary [Internet]. Springfield (MA): MerriamWebster Incorporated; 2016. Selfie; [cited 2017 May 3]; [about 1 screen]. Available from: https://www.merriam-webster.com/dictionary/ selfie.

5. OED Online [Internet]. Oxford: Oxford University Press; 2018.word of the year 2013; [cited 2018 Oct 25]; [about 1 screen]. Available from: https://en.oxforddictionaries.com/word-of-the-year/word-of-theyear-2013.

6. Mills JS, Musto S, Williams L, Tiggemann M. "Selfie" harm: Effects on mood and body image in young women. Body Image.2018;27:86-92.

7. Chugh $P$, Sharma R, Fahim T. Selfie Elbow-Latest Tech Injury. Int. J. Pharm. Med. Res. 2016;4:376-81.

8. Winter C. German dies after falling off World's End in Sri Lanka trying to take selfie[internet]. Germany:DW; 2018. [Cited 2018 Nov 20]. Available from: https://www.dw.com/en/german-dies-after-fallingoff-worlds-end-in-sri-lanka-trying-to-take-selfie/a-46254192.

9. Corrales N. Selfie in front of Bangui windmills turns deadly [internet].Philippines:Inquirer Interactive, Inc; 2014 [cited 2018 Nov 11]. Available from: https://newsinfo.inquirer.net/644971/selfie-infront-of-bangui-windmills-turns-deadly.

10. Mishra I. Selfie in front of running train costs three college-goers their life[Internet]. India: The Times of India; 2015[cited 2018 Nov 20]. Available from: https://timesofindia.indiatimes.com/india/Selfie-infront-of-running-train-costs-three-college-goers-their-life/ articleshow/46025185.cms.

11. Erviani NK. Singaporean dies when taking selfie in Bali [Internet]. Indonesia:The Jakarta Post; 2015. [Cited 2018 Nov 20]. Available from: http://www.thejakartapost.com/news/2015/05/22/singaporeandies-when-taking-selfie-bali.html.

12. Kaplan S. Man accidentally kills himself 'while taking selfie with a gun'[Internet]. United Kingdom:The Independent;2016 [Cited 2018 Nov 20]. Available from: https://www.independent. co.uk/news/ world/americas/man-accidentally-kills-himself-while-taking-selfiewith-a-gun-a6909406.html.

13. American Psychiatric Association. 'Selfie' is a mental disorder [internet].Armenia:News.am Medicine ;2016 [updated 2014 April 6; Cited 2018 Nov 11] Available from :https://med.news.am/eng/ news/1435/american-psychiatric-association-selfie-is-a-mentaldisorder.html.

14. Doğan U, Adıgüzel A. Effect of Selfie, Social Network Sites Usage, Number of Photos Shared on Social Network Sites on Happiness among University Students: A Model Testing. J. Educ. Pract.2010;8 (27):140-7.

15. Canillas F, Colino A, Menéndez P. Cellular Phone Overuse as A Cause for Trapeziometacarpal Osteoarthritis: A Two Case Report. J. Orthop. case reports. $2014 ; 4(4): 6-8$.

16. Gustafsson E, Thomée S, Grimby-Ekman A,Hagberg M. Texting on mobile phones and musculoskeletal disorders in young adults: A fiveyear cohort study. Appl. Ergon.2017;58: 208-14.

17. Lee $\mathrm{M}$, Hong $\mathrm{Y}$, Lee SWon J, Yang J, Park S,et al. The effects of smartphone use on upper extremity muscle activity and pain threshold. J. Phys. Ther. Sci.2015;27(6): 1743-5.

18. Nanda S. Selfie Elbow : Selfie addiction causes this medical condition [Internet]. Be Fit and Fine ;2016. [Cited 2018 Nov 20]. Available from: https://www.befitandfine.com/selfie-elbow-addiction/.

19. Vats M. Selfie syndrome: An Infectious Gift of IT to Health Care. J. Lung, Pulm. Respir. Res.2015;2 (4): 70-1.

20. Standring S. Gray's anatomy: the anatomical basis of clinical practice. 40th ed. edinburgh: Churchill Livingstone/Elsevier; 2008.p. 831-37.

21. Kruszelnicki K. A brief history of the selfie [Internet]. Australia:ABC Science; 2014. [Cited 2017 May 3]. Available from: http://www.abc. net.au/science/articles/2014/08/12/4065062.htm.

22. Asrah J. Selfie Elbow [Internet]. India:PT alert; 2016. [Cited 2017 May 8] Available from: http://ptalert.blogspot.com/2016/08/selfieelbow.html?spref=fb. 
23. Min CH. The 'selfie elbow' is the latest in tech injuries [Internet]. Singapore:The straits Times;2016 [Cited 2017 May 3]. Available from: http://www.straitstimes.com/singapore/the-selfie-elbow-is-thelatest-in-tech-injuries.

24. Mitral P. Now, 'selfie elbow' becoming new medical condition [Internet]. India: The Times of India; 2016 [Cited 2018 Nov 20]. Available form: http://timesofindia.indiatimes.com/ city/kolkata/ Now-selfie-elbow-becoming-new-medical-condition/articleshow/ 53136829.cms.

25. Singh V.Text Book of Anatomy. 2nd edition. New Delhi: Reed Elsevier India Private Limited; 2014. 145p.

26. Inagaki K. Current concepts of elbow-joint disorders and their treatment. J. Orthop. Sci. 2013; 18: 1-7.

27. Singh, V.Text Book of Anatomy. 2nd edition. New Delhi: Reed Elsevier India Private Limited; 2014. 144p.

28. Saggio J. 'Selfie elbow?' 'Text neck?' Medical language changing as smartphone use creates new issues [Internet]. USA:Florida Today; 2018 [Cited 2018 Nov 20]. Available from:https://www. floridatoday. com/story/news/2018/03/16/selfie-elbow-text-neck-medical-languagechanging-smartphone-use-creates-new-issues/ 420544002/
29. IANS. 'Selfie Elbow' condition waiting to afflict Indians [Internet]. India:The Indian Express;2016[Cited 2017 May 3].Available from: http://indianexpress.com/article/lifestyle/health/selfie-elbowcondition-waiting-to-afflict-indians-2917821/.

30. Kela R, Khan N, Saraswat R, Amin B. Selfie: Enjoyment or Addiction? J. Med. Sci. Clin. Res.2017; 05: 15836-40.

31. Jobe C. Lateral and Medial Epicondylitis of the Elbow. J. Am. Acad. Orthop. Surg.1994;2(1): 1-8.

32. Stanish WD, Rubinovich RM, Curwin S. Eccentric exercise in chronic tendinitis. Clin. Orthop. Relat. Res.1986;20 (8):65-8.

33. Pensini M, Martin A, Maffiuletti NA. Central Versus Peripheral Adaptations Following Eccentric Resistance Training. Int. J. Sports Med.2002;23(8): 567-74.

34. Pienimäki TT, Tarvainen TK, Siira PT, Vanharanta H. Progressive strengthening and stretching exercises and ultrasound for chronic lateral epicondylitis. Physiotherapy.1996;82(9):522-30.

35. Sevier TL, Wilson JK. Treating Lateral Epicondylitis. Sport. Med.1999;28(5): 375-80.

36. Gupta R, Pooja M. Selfie an infectious gift of IT to modern society. Glob. J. Res. Anal.2016;5(1): 278-80. 